\title{
Analysis of Enhanced Pool Boiling Heat Transfer on Laser-Textured Surfaces
}

\author{
Łukasz J. Orman ${ }^{1, *}$, Norbert Radek ${ }^{2}$, Jacek Pietraszek ${ }^{3 \oplus}$ and Marcin Szczepaniak ${ }^{4}$ \\ 1 Faculty of Environmental, Geomatic and Energy Engineering, Kielce University of Technology, \\ al. Tysiaclecia P.P.7., 25-314 Kielce, Poland \\ 2 Faculty of Mechatronics and Mechanical Engineering, Kielce University of Technology, al. Tysiaclecia P.P.7., \\ 25-314 Kielce, Poland; norrad@tu.kielce.pl \\ 3 Faculty of Mechanical Engineering, Cracow University of Technology, al. Jana Pawła II 37, \\ 31-864 Cracow, Poland; jacek.pietraszek@mech.pk.edu.pl \\ 4 Military Institute of Engineer Technology, 50-961 Wrocław, Poland; szczepaniak@witi.wroc.pl \\ * Correspondence: orman@tu.kielce.pl
}

Received: 30 April 2020; Accepted: 26 May 2020; Published: 28 May 2020

check for updates

\begin{abstract}
Enhancement of pool boiling heat transfer can be attained with a number of passive and active techniques. The paper experimentally analyses the impact of laser treatment of the copper surfaces on pool boiling heat transfer of distilled water and ethyl alcohol. The samples were modified with a laser beam to produce longitudinal grooves of highly developed microstructures in the laser textured area. Specimens of different groove depths, groove widths and micro-fin widths were produced. The results indicate a significant influence of laser processing on heat flux dissipated from the surfaces and heat transfer enhancement for all the samples tested. The experimental results have been generalized in the form of a heat flux correlation based on a modified model of enhanced pool boiling heat transfer.
\end{abstract}

Keywords: boiling heat transfer; enhancement; laser texturing

\section{Introduction}

Boiling heat transfer is a phase-change phenomenon, at which considerable heat fluxes are transferred at relatively small temperature differences. Further enhancement is possible with the use of passive and active methods (defined based on the criterion of the presence of direct input of external power). The interest in phase- change heat transfer augmentation techniques stems from the ever-growing need for more efficient, smaller, lighter and more reliable heat exchangers used in many areas of engineering and technology, such as in refrigeration, electronics cooling, nuclear applications, etcetera.

The most advantageous and commonly used are passive techniques. They include treated surfaces of altered morphology, increased roughness, extended heat transfer area, displaced augmentation devices, application of coiled elements, various additives to the liquids, etcetera [1,2]. Within each group, many different structures and microstructures can be distinguished as well as various production technologies can be used in the process of their development. The literature in the area of pool boiling heat transfer enhancement is broad due to decades of research and many recent literature reviews are available (e.g., [3-5]). However, it needs to be noted that despite the large literature database on enhanced pool boiling heat transfer, relatively few experimental works deal with laser-textured surfaces and they are mostly limited to the last several years. Moreover, although laser treatment is generally considered to significantly augment boiling heat transfer, some reports are ambiguous or even prove the opposite effect. 
Kruse et al. [6] experimentally analyzed water pool boiling heat transfer on horizontal stainless steel heaters modified with a femtosecond laser. The produced coatings had self-organized mound-like microstructures covered by dense layers of nanoparticles. Surface roughness ranged from 1.4 to $7.8 \mu \mathrm{m}$, while peak-to-valley height ranged from 7.1 to $35.8 \mu \mathrm{m}$. The critical heat flux of the most efficient modified sample was reported to be almost 1.6 times higher, while the maximal heat transfer coefficient was almost three times higher than in the case of the reference polished sample. It was concluded that the enhancement of heat transfer coefficients is linked with the surface area ratio, structure height as well as active nucleation site density (sites where vapor bubbles grow). At low heat flux values, it is also improved due to more effective bubble departure dynamics. Ho et al. [7] tested the boiling of HFE-7000 fluid on $10 \mathrm{~mm} \times 10 \mathrm{~mm}$ aluminum surfaces, on which microstructures of AlSi10Mg powder were fabricated with the selective laser melting technology. The samples had arrays of $7 \times 7$ microcavities. The cavities were additionally separated by microgrooves. The results indicated over $30 \%$ heat exchange augmentation. Moreover, the microgrooves were observed to be active nucleation sites, as opposed to the cavities that were inactive. A later work by Ho et al. [8] dealt with pool boiling of FC-72 on microcavity and microfin surfaces made with laser from AlSi10Mg base powder. Two microcavity samples of $7 \times 7$ and $9 \times 9$ cavities, separated by grooves were produced. Their average cavity mouth diameters were 500 and $700 \mu \mathrm{m}$, respectively. The average cavity base diameter was measured to be $200 \mu \mathrm{m}$, and $400 \mu \mathrm{m}$ for the latter specimen. The process of selective laser melting also enabled the production of four micro-fin samples. The surfaces consisted of arrays of circular dome-like micro-fins protruding from the base. The number of arrays was: $9 \times 9,11 \times 11$ and $15 \times 15$. Fin base diameters were 350 and $500 \mu \mathrm{m}$, while fin heights were 400 and $550 \mu \mathrm{m}$. Up to $70 \%$ improvement in the mean heat transfer coefficient and $76 \%$ enhancement of the critical heat flux in relation to the plain surface was observed for the microstructured samples. Microcavities provided increased active nucleation site density. The research showed the micro-fin surfaces to be more efficient than microcavity ones. According to the authors, it can be explained by the fact that fins offer additional area for vapor bubble nucleation and enhanced heat dissipation via conduction from the base. Liu et al. [9] also studied FC-72 boiling heat transfer on laser processed surfaces. Structured samples of different spacing and peak-to-valley heights were considered. A significant enhancement of heat transfer coefficient (up to 5.87 times higher than for the smooth surface) and $91 \%$ improvement of the critical heat flux value were recorded for the laser textured heaters.

Voglar et al. [10] investigated water boiling heat transfer on $25-\mu \mathrm{m}$-thick stainless steel foils modified with a nanosecond fiber laser. Three kinds of patterns were produced on the samples: parallel lines, squares and circles. Their laser textured regions had three dimensions: 0.5, 1 and $2 \mathrm{~mm}$. Its roughness was ca. $2.10 \mu \mathrm{m}$, as opposed to $0.16 \mu \mathrm{m}$ for the base surface. All the treated samples enhanced boiling; the heat transfer coefficient was over 4 times higher and the critical heat flux 3.7 times higher in relation to the smooth surface. Zakšek et al. [11] experimentally studied pool boiling of water, ethanol and their mixtures, also on $25-\mu$ m-thick stainless steel foils treated with a pulsed fiber laser. The laser treatment produced textured lines on the samples, whose width ranged from 0.5 to $2.5 \mathrm{~mm}$, separated by $0.5 \mathrm{~mm}$-wide untreated areas. Thus, the pitch (distance between the repeated elements) ranged from 1 to $3 \mathrm{~mm}$. All the laser-modified specimens augmented heat flux in comparison to the reference (untreated) sample over the entire range of heat fluxes. Heat transfer coefficient was maximally 2.8 times bigger than that of the reference heater in the case of pure water and 2.68 for pure ethanol. It was concluded that microcavities formed in the process of laser treatment increase the nucleation site density and nucleation frequency as well as decrease the temperature of the onset of nucleate boiling. Gregorčič et al. [12] tested distilled water and FC-72 pool boiling on horizontal stainless steel foils, in which artificial cavities were made using a nanosecond fiber laser. The samples had square spots of $0.5 \times 0.5 \mathrm{~mm}^{2}$, but different microtextures made onto them in the form of channels separated by $80 \mu \mathrm{m}$ and $40-50 \mu \mathrm{m}$. It was reported that the nucleation site density increased over seven times in comparison with the smooth surface and the surfaces with laser textured array of squares enhanced heat transfer of both tested polar and dielectric fluids. 
Zupančič et al. [13] investigated boiling of distilled water on stainless steel foils, whose surfaces were modified with a nanosecond laser. The lines produced in the samples were separated from each other by 10 to $200 \mu \mathrm{m}$. It was reported that the laser treatment led to $110 \%$ higher heat transfer coefficients as well as 20-40 times higher active nucleation site densities in comparison with the untreated surface. Experiments performed on the same type of heaters ( $25 \mu \mathrm{m}$-thick stainless steel foils) and the same working fluid, but with polydimethylsiloxane-silica coatings treated with or without a nanosecond laser were presented in [14]. It was found that almost all of the modified surfaces produced smaller bubbles, higher nucleation frequency and larger densities of active nucleation sites than in the case of the smooth reference surface. The only exception was the sample with relatively shallow microstructures with no microcavities, whose performance was similar to that of the smooth surface. The test results of boiling performance of polydimethylsiloxane-silica laser treated coatings were also given in [15]. The samples' surfaces were modified with the laser to produce square patterns of $0.25 ; 1$ and $2 \mathrm{~mm}^{2}$ spot sizes. The sample with $0.25 \mathrm{~mm}^{2}$ spot size proved to dissipate the largest heat fluxes among all the specimens, while the performance of the other two were similar to one another. The critical heat flux value of the most efficient sample was up to $200 \%$ higher in relation to the smooth stainless steel.

Sitar et al. [16] carried out an experimental study of water pool boiling on $10 \times 10 \mathrm{~mm}^{2}$ silicon specimens. The samples were textured with laser or covered with etched artificial cavities (fabricated in a plasma etcher). The smooth surface's roughness was $0.65 \mathrm{~nm}$, while after laser treatment it amounted to $646-2788 \mathrm{~nm}$. The performance of laser textured heaters was worse than in the case of the samples with etched cavities, but generally better than the smooth reference surface (although some laser treated samples at certain superheats performed worse than the smooth surface). Može et al. [17] focused their paper on distilled water pool boiling and stability of heater surfaces modified with laser. Two copper specimens of $18 \mathrm{~mm}$ diameter were tested after laser texturing with a nanosecond fiber laser (one made in air and the other in an argon atmosphere). The critical heat flux enhancement of both laser textured specimens was almost $90 \%$, while the heat transfer coefficient of over $115 \%$ compared to the smooth surface mostly due to increased active nucleation site density. The authors claimed that the smooth surface showed a tendency of constant shifts with every experimental run, while the shift for laser treated heaters occurred just once. Thus, these surfaces proved to be more stable.

Grabas [18] presented test results of distilled water boiling on horizontal AISI 304 steel heaters of $30 \mathrm{~mm}$ diameter. The heat exchangers were modified using laser treatment and simultaneous vibrations of the surfaces. The average roughness ranged from 0.733 to $20.202 \mu \mathrm{m}$, while the technically smooth surface roughness was much lower and amounted to $0.178 \mu \mathrm{m}$. The laser-vibration textured heaters proved to significantly enhance pool boiling heat transfer. The best performance was observed for the surface with the highest roughness. In this case the heat transfer coefficient increased by over 4 times, while the critical heat flux by about 1.8 times. Karthikeyan et al. [19] studied a combined effect of using laser textured heater surfaces and ethanol-based nanofluids. The authors used femtosecond laser micromachining to produce periodic nanoscale and dual scale roughness microstructures on the copper base. The experiments were performed to estimate the rate at which a sample was cooled from 150 to $90{ }^{\circ} \mathrm{C}$. It was concluded that the combined effect of the two heat augmentation methods enabled obtaining 59\% boiling heat transfer enhancement in relation to the smooth surface and pure base liquid.

Dharmendra et al. [20] tested pool boiling of water on three grooved copper surfaces fabricated with a picosecond laser. The samples had square grooved patterns of the same $100 \mu \mathrm{m}$ pitch and $100 \mu \mathrm{m}$ width, but different depths: 30, 70, and $100 \mu \mathrm{m}$. The results indicate that boiling incipience occurred at lower superheats in the case of laser treated samples (the higher the depth of the texture, the lower the superheat value for boiling initiation). The impact on the heat flux was of similar nature. The sample with the deepest grooves outperformed the others, however all the specimens exhibited much higher heat fluxes than those recorded for the smooth surface (even several times larger). The highest enhancement of heat transfer was observed for small superheats. Nirgude and 
Sahu [21] performed experiments on water and acetone pool boiling on copper heaters treated with a nanosecond laser. The three produced circular specimens had longitudinal grooves. The surface roughness ranged from ca. 0.24 to $0.29 \mu \mathrm{m}$. Enhancement of heat transfer was observed for all the modified samples and boiling was initiated at smaller superheats. The heat transfer coefficient was 1.8 times higher for water and almost 1.6 times higher for acetone in comparison with the smooth reference surface. Orzechowski [22] conducted experiments on a steel fin with longitudinal laser interfusions, located symmetrically across the specimen in the form of micro-fins. Such a laser modified surface proved to enhance boiling especially at low heat flux values. At higher ones, the boiling curves of the treated and untreated samples coincided.

A different type of laser treated structure for pool boiling heat transfer enhancement was proposed by Wang and Leong [23]. The tests were performed with FC-72 as the boiling agent. The porous lattice structures were made with a selective laser melting method, in such a way that the AlSi10Mg powder was first placed evenly on a substrate base and then the laser beam melted this powder to form a pre-programmed structure. The samples had a repeating geometry of octet-truss unit cells, whose cell sizes were 2,3 and $5 \mathrm{~mm}$, while the heights were $2.5,5$ and $10 \mathrm{~mm}$. The porous structures proved to considerably enhance heat transfer. The average heat transfer coefficient was over 2.8 times higher, while the critical heat flux was over 6.1 times higher than in the case of the smooth surface. The enhancement was attributed to increased surface area, higher nucleation site density and capillary-assisted suction of the coatings. Zhang et al. [24] carried out experiments of water pool boiling on 3D grid structures produced with selective laser melting. The structural material was stainless steel. On the square $12 \times 12 \mathrm{~mm}^{2}$ samples microstructures of regular geometry were made. Their height was 0.75 and $1.5 \mathrm{~mm}$, grid width varied from 0.4 to $1.3 \mathrm{~mm}$ while porosity from $42 \%$ to $73 \%$. The critical heat flux was maximally three times higher than that of the smooth surface, however not all the samples enhanced heat transfer in relation to the smooth surface. Generally, it was concluded that the two-phase flow patterns within the microstructures influenced their boiling performance.

Apart from pool boiling, laser treated surfaces are also used to enhance heat transfer in other applications. Piasecka et al. [25] tested vibration-assisted laser textured surfaces in the flow boiling mode of heat transfer. FC-72 was used as the boiling agent. The values of local heat transfer coefficient for the saturated boiling region recorded for the modified surfaces had considerably higher values than those obtained for the smooth surface at the same heat flux. A recent paper by Ventola et al. [26] investigated a laser etching technique to produce metal surfaces of elliptic scale-roughened and cone-patterned heat sinks. The produced samples proved to enhance convective heat transfer in relation to the samples without such micro-protrusions. The authors provided two possible explanations for the augmentation, namely: larger heat transfer area and improved Nusselt number. The favorable influence of the use of laser treatment for convective heat transfer was also confirmed in [27]. The roughness of the laser textured samples was made of micro-metric truncated cones, whose heights ranged from 200 to $1100 \mu \mathrm{m}$. The convective heat transfer coefficient of the best performing laser textured sample was found to be about two times larger compared to the smooth heat sink.

The laser modification of the heater surface provides additional nucleation sites and generally has a favorable impact on pool boiling heat transfer. However, the possibilities of shaping the surface microstructure with the laser beam are very broad. It seems that only a fraction of modification options have been tested so far. Moreover, the influence that the microgeometry of a heater surface has on pool boiling heat transfer requires clarification. More insight into the phenomenon of the boiling process occurring on laser treated surfaces is necessary for the proper design of efficient phase-change heat exchangers that can be used in many areas of engineering and technology. The need for clarification of literature reports and for expanding the knowledge on pool boiling heat transfer on surfaces treated with the laser beam as well as generalizing the obtained results with a modified heat flux correlation have been the motivation behind the current experimental study. 


\section{Materials and Methods}

The research was performed with distilled water as well as dehydrated ethanol as the boiling agents. The samples used in the tests were in the form of $3 \mathrm{~cm}$ diameter copper discs. They underwent laser texturing to produce longitudinal grooves on the whole surface. This method is a precise and highly repeatable manufacturing technique. Once the samples were fabricated, they were soldered to the copper heater and the experimental procedure could begin.

Laser treatment was carried out in an air atmosphere with the SPI G3.1 SP20P pulsed fiber laser with the following process parameters:

- impulse frequency: $60 \mathrm{kHz}$,

- pulse duration: $60 \mathrm{ns,}$

- power: $20 \mathrm{~W}$,

- focal spot size: $35 \mu \mathrm{m}$,

- $\quad$ scanning velocity: $200 \mathrm{~mm} / \mathrm{s}$.

The specimens were designed in such a way to produce grooves of two values of depth, width of the grooves and width of the fins (Table 1). The schematic of a sample has been presented in Figure 1a, while the photograph of sample no 1 in Figure $1 b$.

Table 1. Details of the geometrical parameters of the samples.

\begin{tabular}{cccc}
\hline Sample no & Groove Depth $\mathbf{h}(\mathbf{m m})$ & Groove Width $\mathbf{w}(\mathbf{m m})$ & Fin Width $\mathbf{~}(\mathbf{m m})$ \\
\hline 1 & 0.55 & 1.15 & 1.10 \\
2 & 0.25 & 1.15 & 1.10 \\
3 & 0.55 & 0.60 & 1.10 \\
4 & 0.25 & 0.60 & 1.10 \\
5 & 0.55 & 1.15 & 0.50 \\
6 & 0.25 & 1.15 & 0.50 \\
\hline
\end{tabular}

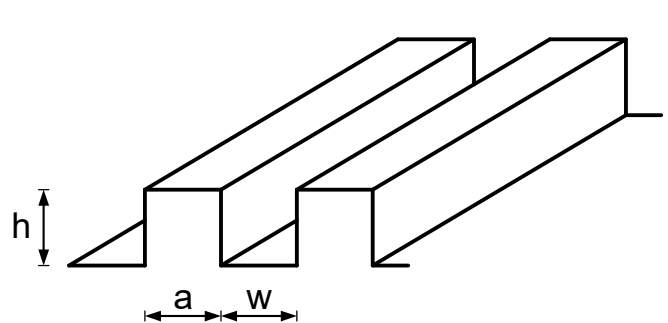

(a)

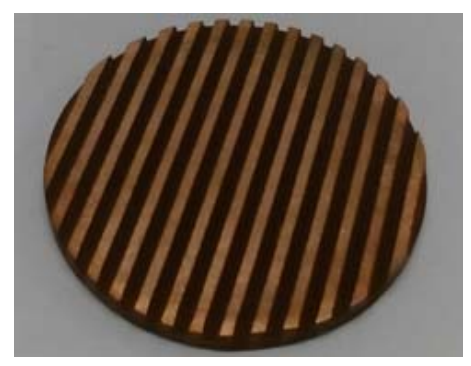

(b)

Figure 1. Laser treated sample. Schematic (a), picture of sample no 1 (b).

As can be seen, laser treatment enabled to produce regular structures on the surfaces. However, despite a high level of regularity there are elements on the edges of the generated grooves that seem to take the random form of mound - like microstructures of various heights as presented in Figure 2. 


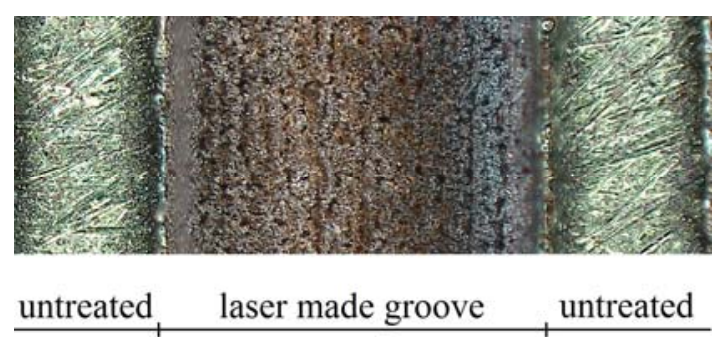

(a)

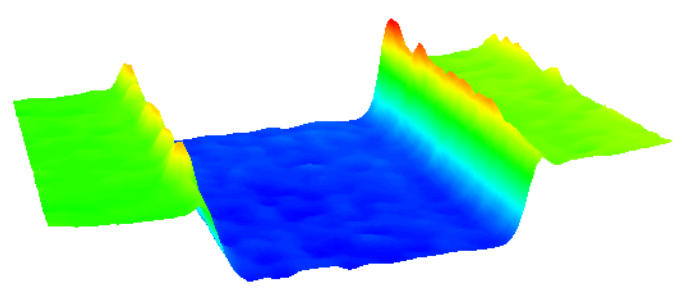

(b)

Figure 2. Images of the groove of sample no 5 (from Hirox optical microscope), magnification 140x: 2D image (a), 3D image in pseudo color (b).

The laser beam produced grooves, whose surface had been significantly modified in comparison to the base material. It became more developed and cavities were created. The mean value of surface roughness was $6.397 \mu \mathrm{m}$. It is ca. nine times the value of roughness recorded for the smooth surface, namely $0.716 \mu \mathrm{m}$. Table 2 presents the details of the roughness profiles, which contains the arithmetical mean deviation $\left(R_{a}\right)$ with its standard deviation, maximum valley depth $\left(R_{v}\right)$ and maximum peak height $\left(R_{p}\right)$ for both types of surfaces.

Table 2. Details of the surface roughness.

\begin{tabular}{ccccc}
\hline Parameter & Mean $(\mu \mathrm{m})$ & Standard Deviation $(\mu \mathrm{m})$ & Minimum $(\mu \mathrm{m})$ & Maximum $(\mu \mathrm{m})$ \\
\hline \multicolumn{5}{c}{ smooth surface } \\
$\mathrm{R}_{\mathrm{a}}$ & 0.716 & 0.084 & 0.503 & 0.964 \\
$\mathrm{R}_{\mathrm{v}}$ & 2.647 & 0.493 & 1.828 & 3.867 \\
$\mathrm{R}_{\mathrm{p}}$ & 2.279 & 0.488 & 1.477 & 4.181 \\
\hline \multicolumn{5}{c}{ laser treated surface } \\
$\mathrm{R}_{\mathrm{a}}$ & 6.397 & 1.192 & 3.471 & 8.948 \\
$\mathrm{R}_{\mathrm{v}}$ & 19.188 & 5.194 & 10.846 & 32.360 \\
$\mathrm{R}_{\mathrm{p}}$ & 16.615 & 3.149 & 8.713 & 25.114 \\
\hline
\end{tabular}

Figure 3a,b present the morphology of the laser treated and smooth surface elements, respectively.

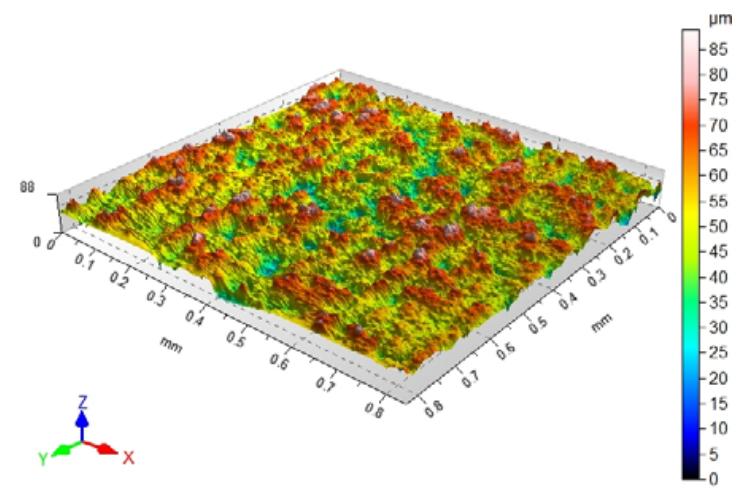

(a)

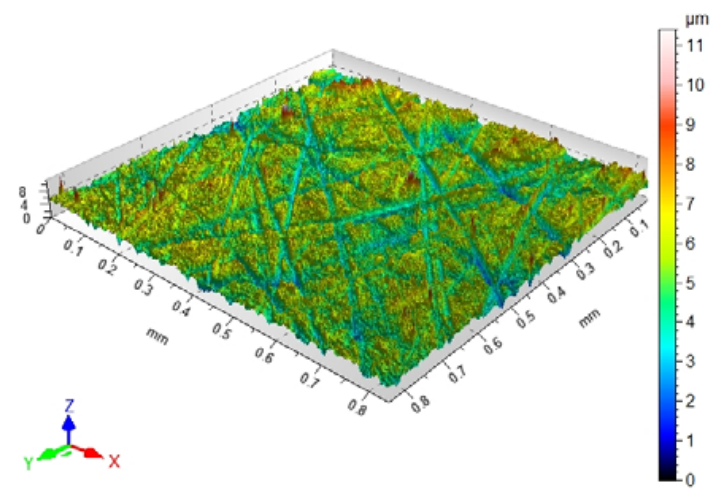

(b)

Figure 3. Images of surface morphology of laser treated (a) and smooth (b) elements.

Having analyzed Figures 1-3 it can be stated that the produced samples have been modified in two ways. In the larger scale, it is surface extension with the longitudinal fins, while in the "microscale" the increased roughness and the presence of cavities. All of these elements are generally considered to have 
a favorable influence on phase-change heat transfer enhancement. Consequently, such a combination might lead to significantly higher heat fluxes being transferred from the laser textured surfaces.

The general concept of the measurement technique and experimental set-up design is commonly used by researchers (for example $[18,20,28]$ ) and widely accepted for these type of tests. In the current project the laser treated samples were mounted onto a heating block and soldered to ensure proper contact. It was the main element of the set-up. An electric heater was located vertically within this block, which provided a source of heat. Around the samples, onto a Teflon plate, a glass vessel was placed. The cooling system enabled the generated vapor to be condensed and flowed down. The temperature measurements were performed with thermocouples (type K): 2 located below the tested surfaces and 3 in the heating block (as in Figure 4). The measurements were done with the Keithley 2700 data logging device equipped with the extension card to enable up to 20 simultaneous measurements. Ice point reference was provided with TRCIII ice bath by OMEGA. An electric cartridge heater was supplied with an autotransformer to increase the power at certain steps. Thus, consecutive data points could have been determined.

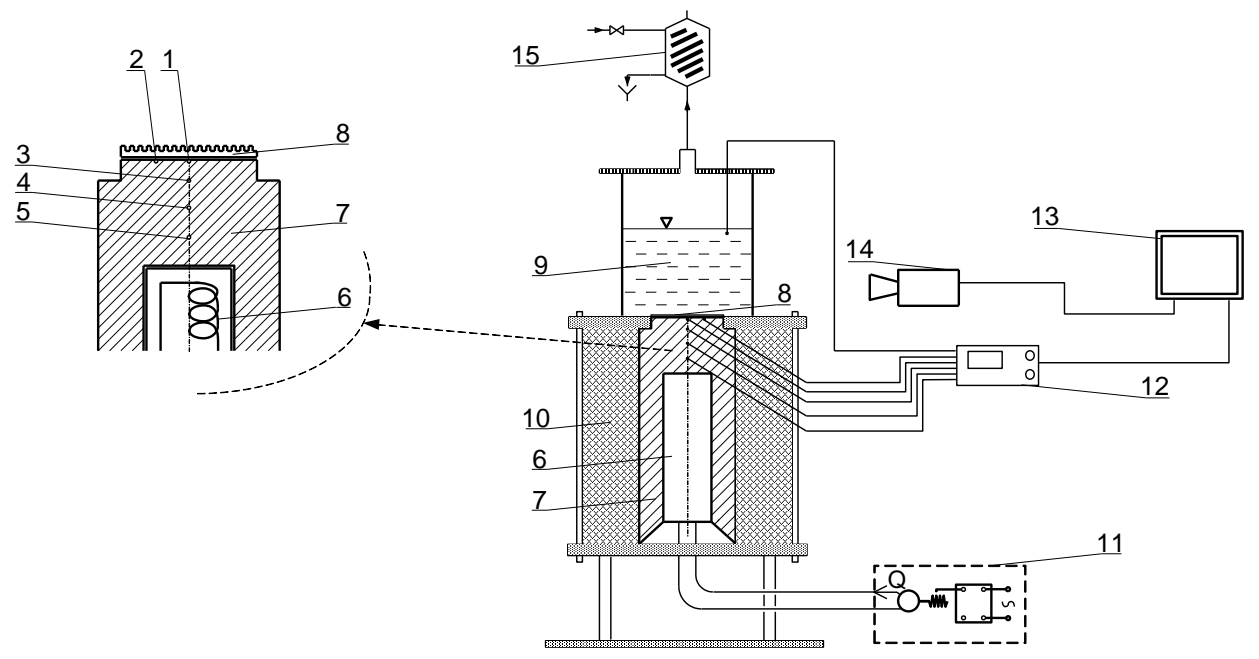

Figure 4. The testing facility: 1 and 2, thermocouples below the specimen; 3,4 and 5 , thermocouples within the solid block; 6, heating device; 7, solid block; 8, laser treated specimen; 9, pool of fluid; 10 , high temperature insulating material; 11 , power supply unit; 12 , temperature recording system, 13, measurements collection unit; 14, camera; 15, water-cooled coil.

Heat flux values were calculated based on the equation that considers the temperature change between the thermocouples according to one-dimensional conduction heat transfer according to:

$$
\mathrm{q}=\frac{\lambda_{\mathrm{Cu}}}{\mathrm{l}_{5-3}}\left(\mathrm{~T}_{5}-\mathrm{T}_{3}\right)
$$

where $T_{3,5}$ are values of temperature (as in Figure 4 ), $1_{5-3}$ is the distance between thermocouples 5 and $3(15.97 \mathrm{~mm})$. For verification purposes heat flux was also calculated between thermocouples 5 and 4 as well as 4 and 3 using the same formula ( $1_{5-4}$ equaled $7.72 \mathrm{~mm}$ and $l_{4-3}$ equaled $8.25 \mathrm{~mm}$ ).

The applied method of one-dimensional conduction given below was already used in other projects found in literature, for example, in $[28,29]$. Temperature on the surface, on which the laser textured samples were located, was determined with the equation below:

$$
\mathrm{T}=\mathrm{T}_{1,2}-\frac{\mathrm{ql}_{\mathrm{a}}}{\lambda_{\mathrm{Cu}}}
$$


where $l_{a}$ is a length measured between thermocouples 1 and 2 (Figure 4$)$ and the heater $(1=3.25 \mathrm{~mm}$ ), while $\mathrm{T}_{1,2}$ is the arithmetic average of both ( 1 and 2$)$ measurements. The values of superheat could be calculated as:

$$
\theta=\mathrm{T}-\mathrm{T}_{\text {sat }}
$$

Using derived values, boiling curves (representing a dependence of heat flux vs. superheat) were generated for each sample and boiling agent.

The experimental uncertainty was determined with the methodology given in [30]. Its value in relation to heat flux determination can be calculated according to the following equation:

$$
\Delta \mathrm{q}=\sqrt{\left(\frac{\partial \mathrm{q}}{\partial \mathrm{l}_{5-3}} \Delta \mathrm{l}_{5-3}\right)^{2}+\left(\frac{\partial \mathrm{q}}{\partial \lambda_{\mathrm{Cu}}} \Delta \lambda_{\mathrm{Cu}}\right)^{2}+\left(\frac{\partial \mathrm{q}}{\partial\left(\mathrm{T}_{5}-\mathrm{T}_{3}\right)} \Delta\left(\mathrm{T}_{5}-\mathrm{T}_{3}\right)\right)^{2}},
$$

where $\Delta$ describes determining uncertainties of temperature, length and conductivity values. Temperature was determined with the maximal uncertainty of $\pm 0.2 \mathrm{~K}$ (consequently, its difference of $\pm 0.4 \mathrm{~K}$ ) for the current experimental unit. The accuracy for length and conductivity were $\pm 0.0001 \mathrm{~m}$ and $\pm 0.25 \mathrm{~W} /(\mathrm{mK})$, respectively. The results of the uncertainty calculations for water are within the range of $3.2 \%$ (for the maximal heat flux $299.3 \mathrm{~kW} / \mathrm{m}^{2}$ ) to $20.6 \%$ (for the lowest one $46.3 \mathrm{~kW} / \mathrm{m}^{2}$ ), while for ethanol they were $4.5 \%$ (at $213.6 \mathrm{~kW} / \mathrm{m}^{2}$ ) to $54.4 \%$ (at $17.5 \mathrm{~kW} / \mathrm{m}^{2}$ ). The results of the respective calculations regarding superheat uncertainly led to the value of ca. $7.7 \%$ (at the water boiling heat flux of $200 \mathrm{~kW} / \mathrm{m}^{2}$ and the temperature value below the specimen of $380 \mathrm{~K}$ ). This value diminishes as the heat flux rises. The obtained results are generally of a similar trend and values to those reported in $[28,29]$.

Prior to the experiments on laser treated samples, the smooth surface was investigated and the test results were compared with the literature data on the same type of samples. The well known and established correlations were considered [31-33]. Additionally, the experimental results adopted from literature on water pool boiling on horizontal smooth copper surfaces presented by Zhao and Zhang [34], Li et al. [35], Xin and Chao [36], Nirgude and Sahu [21] and very recently by Dharmendra et al. [20]. The results have been presented in Figure 5.

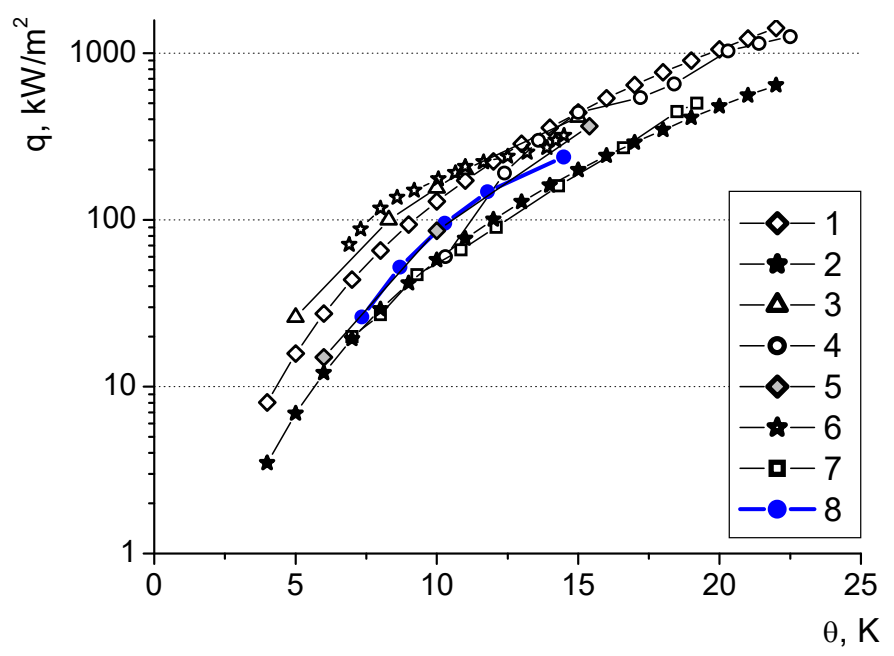

Figure 5. Validation of the experimental method: data for current smooth sample water boiling (8) vs. literature based calculations and raw data. 1, model [31] with constants by [32]; 2, correlation [33]; 3,4,5,6 and 7, horizontal smooth copper surface test results, data adopted from [34-36], [20,21], respectively.

As can be seen in Figure 5, the present study data points fall within those obtained by other researchers for the same material and surface type as well as two pool boiling heat flux correlations. 
Thus, we may state that the current experimental methodology used for the present investigation provides reliable results.

\section{Results and Discussion}

\subsection{Nucleate Boiling Test Results of Laser Textured Surfaces}

The tests of pool boiling heat transfer were conducted for two boiling agents under ambient pressure. As a result of laser texturing the surface geometry and microgeometry of the samples were modified. The analysis of the effects of microgeometry of the designed specimens on nucleate boiling heat flux was focused on the influence of the groove depth, its width as well as the fin's width.

Figure $6 \mathrm{a}, \mathrm{b}$ represent the boiling curves for samples no 1, 2, 3 and 4 of the same fin width, but different groove width $(0.60 \mathrm{~mm}, 1.15 \mathrm{~mm})$ and different groove depths $(0.25 \mathrm{~mm}, 0.55 \mathrm{~mm})$.

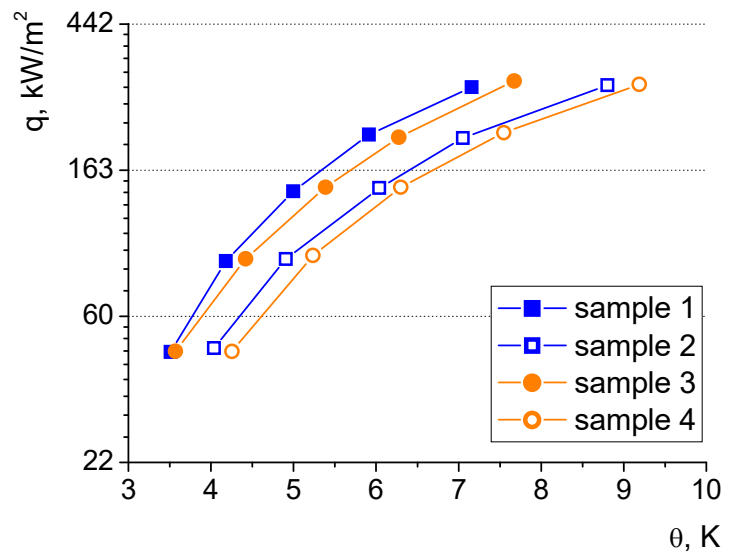

(a)

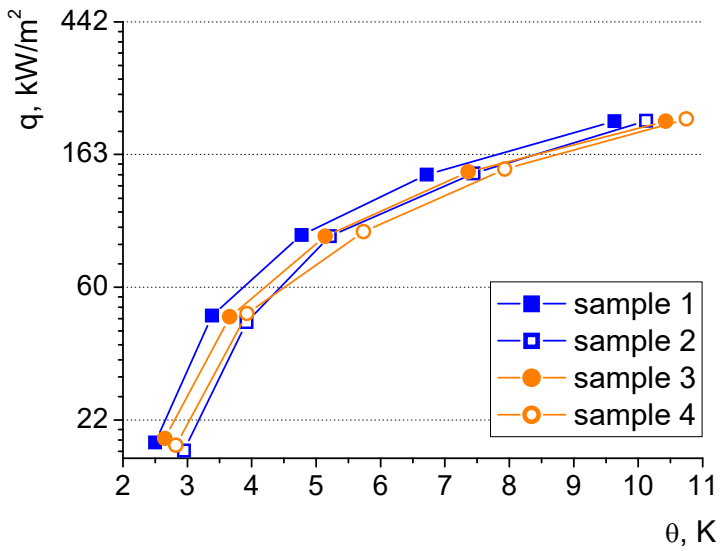

(b)

Figure 6. Heat flux vs. wall superheat for samples of different groove width and depth; (a) distilled water, (b) ethyl alcohol.

The specimens with deeper grooves (thus, longer fins) performed better than the shallow ones (sample pairs 1,2 and 3,4). It is apparent with the shift of the boiling curves to the areas of lower superheats at the same heat flux transferred to the samples. It might be mainly related to the increased heat transfer surface area of the deeply grooved specimens (by about $22 \%$ for the sample pairs 1,2 and $27 \%$ for 3,4$)$.

The same phenomenon of boiling curves' shift can be observed if the surfaces with larger groove widths are compared to the narrower ones. The specimens with wider grooves outperformed those with half their groove width (sample pairs 1,3 and 2,4) at the same fin width. It proves the favorable impact of the microstructural surface of high roughness produced with the laser beam and located at the base of the grooves. Moreover, the heat transfer surface area of sample 1 is over $10 \%$ higher than that of sample 3 (and 6\% larger for sample 2 in relation to sample 4), which might also have an additional favorable effect.

Figure $7 \mathrm{a}, \mathrm{b}$ represent the performance of the samples, whose groove width is constant $(1.15 \mathrm{~mm})$, but the fin width varies $(0.50$ and $1.10 \mathrm{~mm}$ ) as well as the fin height (namely groove depth of $0.25 \mathrm{~mm}$ and $0.55 \mathrm{~mm}$ ). The analysis of the figures confirms the finding that specimens of deeper grooves performed better for the considered range of height values $0.25-0.55 \mathrm{~mm}$. It also indicates that the samples of narrower fins (and, thus, larger laser textured area) provided the best performance (sample pairs 1,5 and 2,6). It might be related to increased heat transfer area since in the case of sample 5, this area is larger by $12 \%$ in comparison to sample 1, while in the case of sample 6 it is almost $7 \%$ higher than the area of sample 2. However, the analysis of the boiling curves of sample pairs 3,5 and 4,6 (Figure 8) might not confirm the assumption of a decisive role of this factor. 


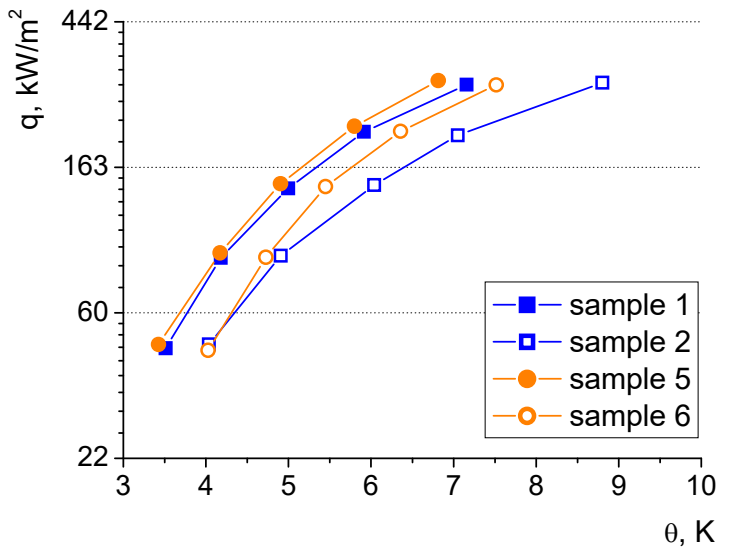

(a)

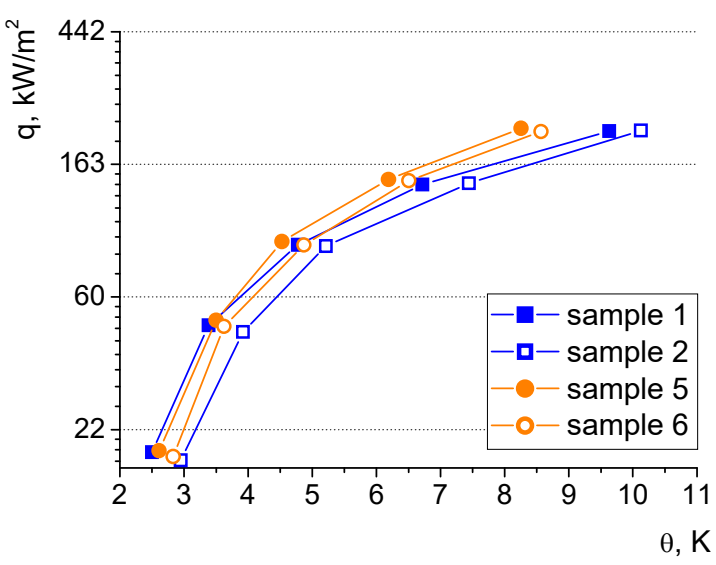

(b)

Figure 7. Heat flux vs. wall superheat for samples of different fin width and height; (a) distilled water, (b) ethyl alcohol.

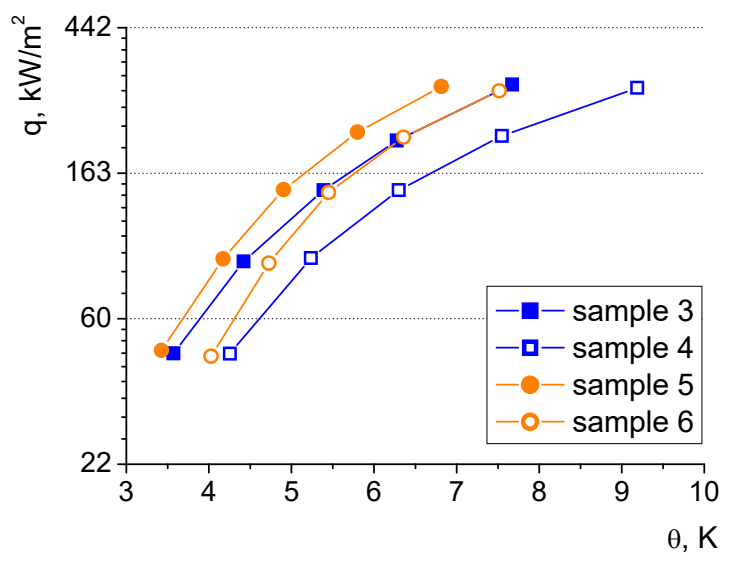

(a)

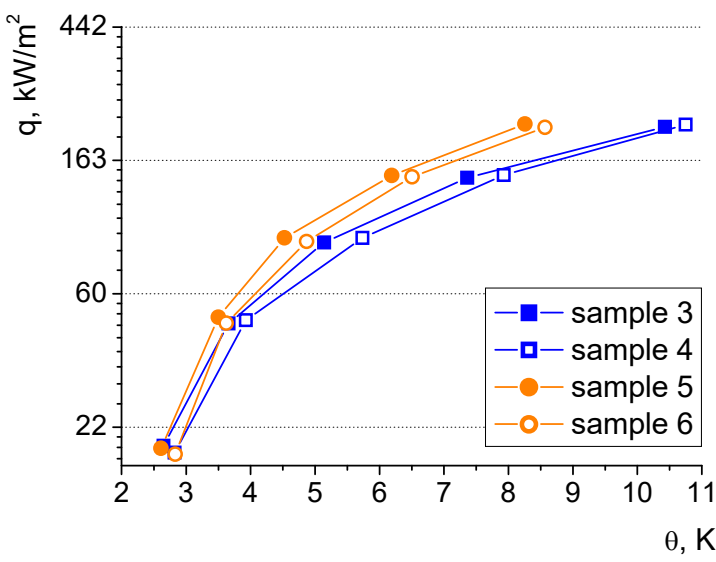

(b)

Figure 8. Heat flux vs. wall superheat for samples of comparable heat transfer areas; (a) distilled water, (b) ethyl alcohol.

The surface areas of specimens 3 and 5 (as well as 4 and 6) are almost identical. However, the performance of those sample pairs is different (specimen 5 outperforms number 3 , while sample 6 outperforms number 4 ). Thus, the boiling heat transfer of laser treated surfaces seems to be more affected by another factor, namely the presence of laser induced high roughness areas. Figure 9 presents the boiling curves of samples of the same groove depth of $0.25 \mathrm{~mm}$, but different groove and fin widths in order to reveal a possible influence of the ratio of surface area textured with laser to the total surface area. This ratio amounts to $53 \%, 42 \%$ and $27 \%$ for samples 6,2 and 4 , respectively.

The influence of laser processing, as a result of which considerable surface roughness and artificial cavities are developed, is clearly visible in the above figures, especially in the case of distilled water as the boiling agent. As the proportion of the textured surface increases, thermal performance improves. The most significant enhancement can be observed for the sample with the largest ratio value of $53 \%$, while the weakest for the smallest $(27 \%)$. In the case of the deeper samples $(\mathrm{h}=0.55 \mathrm{~mm})$ this ratio is smaller and amounts to $42 \%, 34 \%$ and $21 \%$ for samples 5,1 and 3, respectively. The percentage difference is lower and the impact of this parameter also seems to be less pronounced as can be seen in Figure 10. 


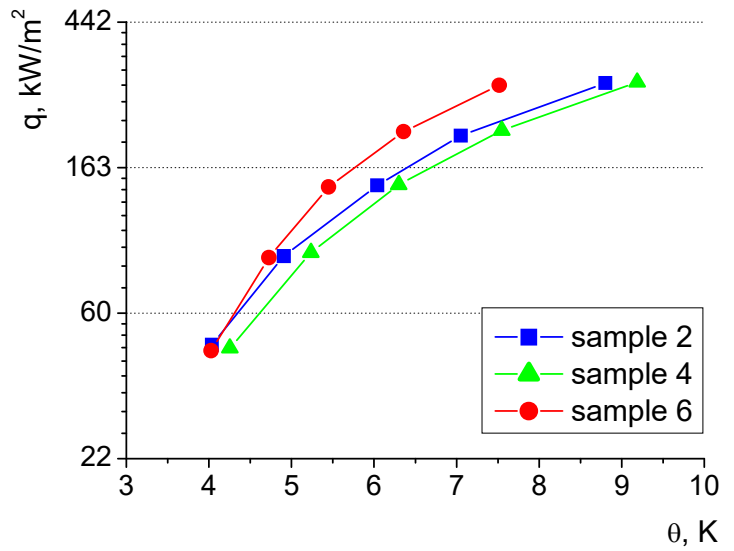

(a)

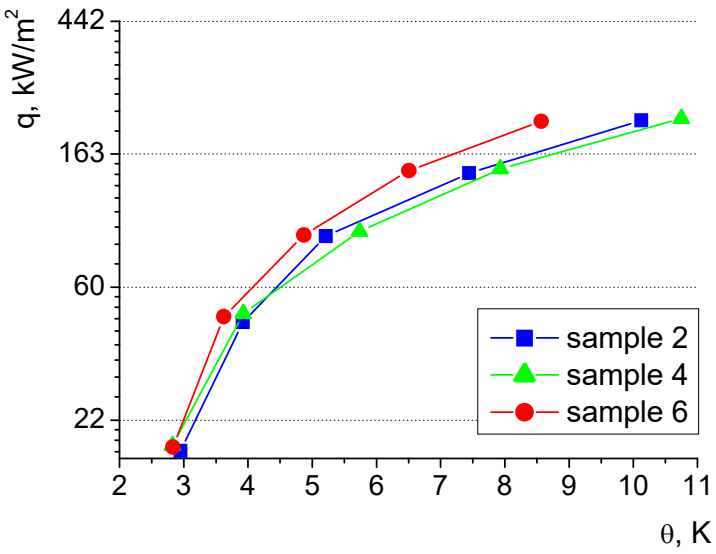

(b)

Figure 9. Boiling curves of samples of various ratio of surface area textured with laser to the total surface area (groove depth, $0.25 \mathrm{~mm}$ ); (a) distilled water, (b) ethyl alcohol.

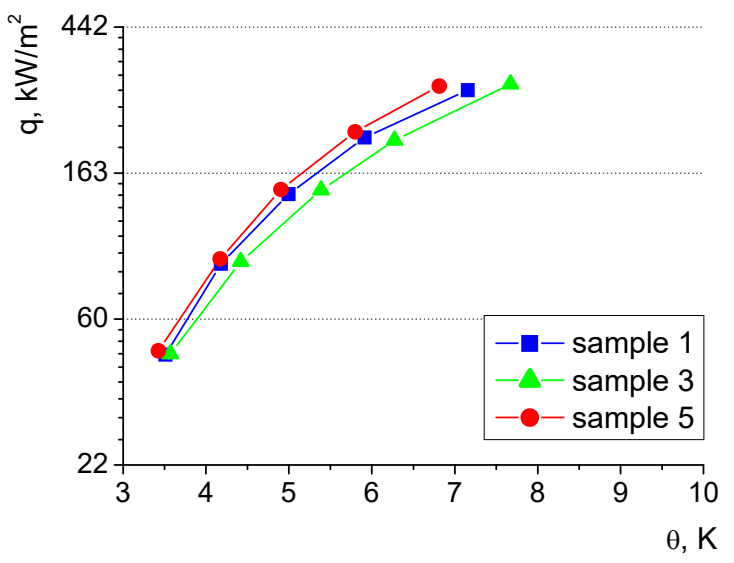

(a)

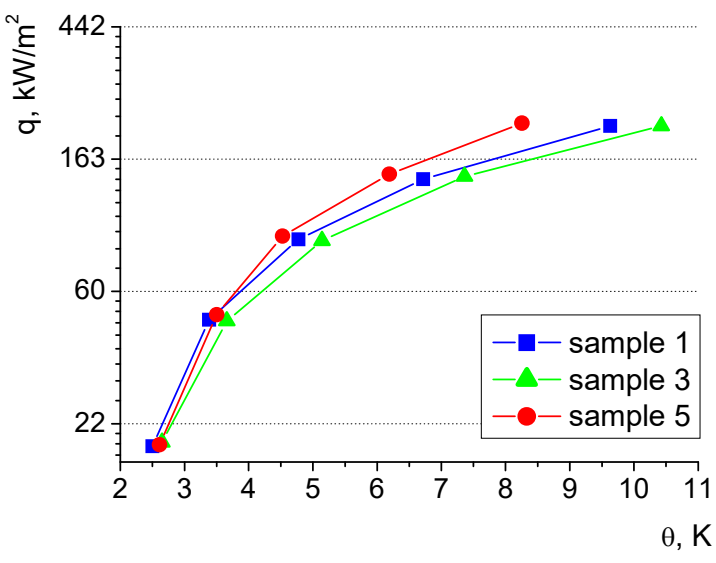

(b)

Figure 10. Boiling curves of samples of various ratio of surface area textured with laser to the total surface area (groove depth, $0.55 \mathrm{~mm}$ ); (a) distilled water, (b) ethyl alcohol.

All laser treated surfaces significantly enhanced pool boiling heat transfer in relation to the smooth reference surface. In the considered region of low heat flux nucleate boiling mode all the laser treated specimens outperformed the smooth surface as presented in Figure 11.

The highest enhancement of pool boiling heat transfer occurred at low heat fluxes, while at higher ones the results obtained for the treated surfaces seem to approach those of the smooth surface. These features of enhanced pool boiling heat transfer have been observed for other passive techniques [37-39] as well as some laser textured surfaces (e.g., [20,22]). Moreover, Figure 11 indicates that boiling was initiated at much lower superheats than in the case of the smooth surface. This phenomenon has also been recorded for other microstructural coatings as well as laser textured surfaces (e.g., [11,20,21]). 


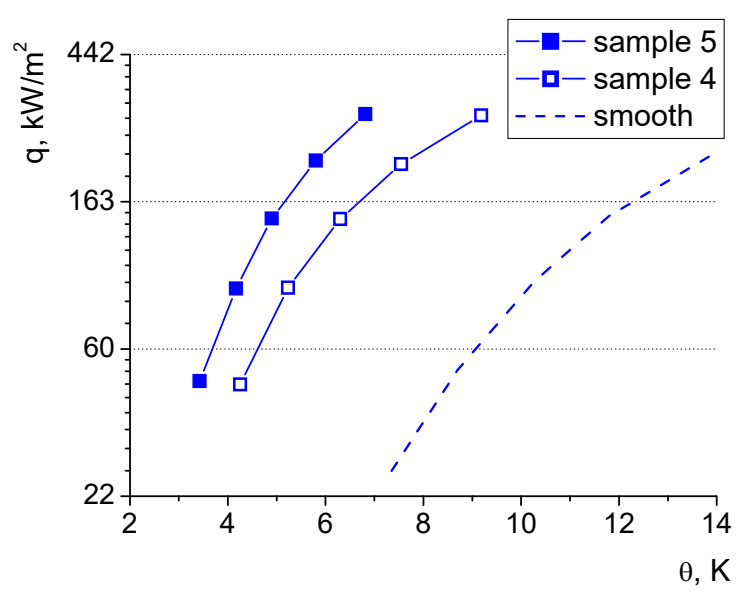

(a)

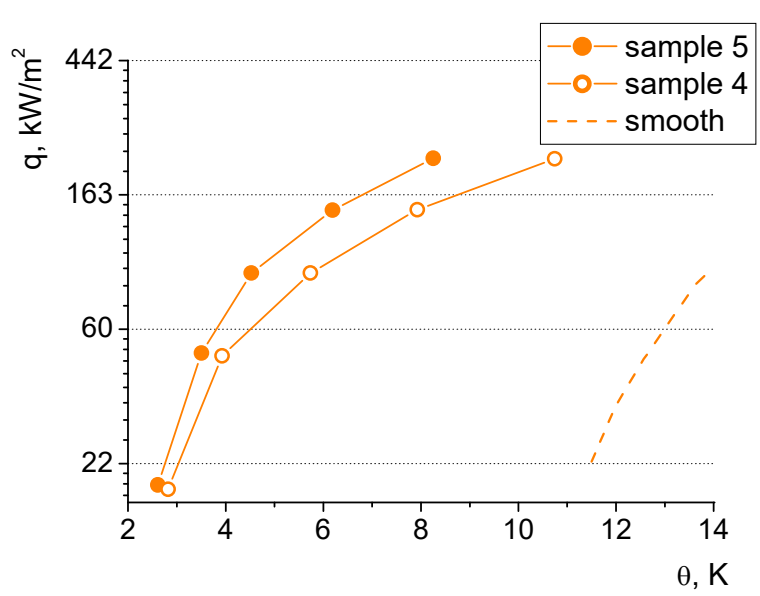

(b)

Figure 11. Comparison of the boiling curves for the most (sample 5) and least (sample 4) efficient laser textured surfaces and the smooth reference surface; (a) distilled water, (b) ethyl alcohol.

Apart from the surface microstructure morphology, the fluid properties have an impact on the boiling process. However, distinguishing their individual contributions is hard and some reports provide conflicting information as indicated in [40]. Surface tension is considered to be one of the most vital properties of the fluid for nucleate pool boiling heat transfer [41]. The test results [42] of pool boiling of water, carbon tetrachloride, $\mathrm{n}$-hexane and acetone proved that surface tension affects the nucleation site density (and thus, the heat flux value). Increased liquid thermal conductivity also seems to have a favorable effect. Elevated values of this parameter in the case of nanofluids augmented boiling at dilute concentrations typically at small and moderate values of heat flux [43]. Gorenflo et al. [44] found that the dependence of the heat transfer coefficient on the fluid's thermophysical properties is also affected by the microstructure of the heater surface. In the case of treated surfaces, Cai and Bhunia [45] investigated the effect of fluid properties in heat pipes with copper wicks. Water, ethyl alcohol and Novec 7200 were the working fluids. The authors reported that the value of the heat transfer coefficient was influenced by liquid thermal conductivity, while the critical heat flux value scales with merit number (which relates liquid density, surface tension, viscosity as well as heat of vaporization). Among the investigated agents, water had the highest surface tension, heat of vaporization and thermal conductivity, while Novec 7200 the lowest. Based on the presented results, it can be seen that in the fully developed nucleate boiling mode, the values of heat flux dissipated with water as the boiling agent were highest and with Novec 7200 the lowest. Heat fluxes for water were maximally about 1.5 times higher than for ethanol. It is generally in agreement with the present study, although for the current investigation of laser-treated surfaces the performance of water proved to be slightly better with the enhancement reaching about two times. In terms of the surface characteristics, Zupančič et al. [15] reported that laser treatment can be used to produce hydrophobic surfaces of high heat transfer enhancing potential. It was confirmed by a study on fluoropolymer coatings, where a significant water boiling enhancement by the application of hydrophobic coatings was reported [46]. Fundamental tests by Gao et al. [47] of water droplets evaporating off heated surfaces showed that the evaporation time from hydrophobic surfaces was higher than from the hydrophilic ones. The hydrophobic surfaces tested in [48] showed increased bubble release rates, while hydrophobic texturing provided a larger number of nucleation sites and elevated value of the critical heat flux. Jo et al. [49] compared the nucleate boiling performance of hydrophilic, hydrophobic and heterogeneous heaters. The authors reported that in the range of low heat fluxes hydrophobic surfaces outperformed the hydrophilic ones, while the best performance was observed for the heterogeneous heater (consisting of hydrophobic dots on a hydrophilic surface). While Yim et al. [50], who analyzed water boiling heat transfer on $\mathrm{TiO}_{2}$ coated hydrophilic and $\mathrm{TiO}_{2}$-water repellent samples, stated that the 
hydrophilic surface proved to have the most efficient increase of pool boiling performance of over $64 \%$ in relation to the smooth surface. The water repellent coated specimen enhanced heat transfer in comparison to the reference surface only at superheats below $12.3^{\circ} \mathrm{C}$.

Despite the influence of a number of factors on pool boiling, it needs to be noted that laser processing can produce efficient surfaces for boiling enhancement with even very diverse boiling agents such as water (a polar fluid of large surface tension and heat of vaporization) and FC-72 (a non-polar liquid of low surface tension and latent heat) as reported in [12].

\subsection{Boiling Heat Flux Correlation of the Test Results}

Boiling is a complex phase-change process and the development of a successful model of this phenomenon and a precise method of heat flux determination has attracted attention for decades. Up to now, such precise and universal models are not available and still scientific effort is made in this area, both in terms of pool boiling heat transfer on the smooth [51] and enhanced [52] surfaces.

The laser treated surfaces considered in the present study have a regular geometry of longitudinal fins. Thus, a model by Smirnov [53] has been selected as a basis for modification. It was based on the assumption that the heat transfer enhancing microstructure can be treated as a matrix of micro-fins. However, this model did not consider the height of the microstructure, which proved to be a crucial parameter in terms of the laser textured surfaces tested. Moreover, other modifications have been introduced to the original model, namely the assumption that heat transfer occurs also at the tips of the micro-fins, which has been taken into account by increasing the height of the structure by half of the width.

The following equation describes the temperature change along the micro-fin (namely, the depth of the groove as presented in Figure 1):

$$
\frac{d^{2}\left(T_{m}-T_{v}\right)}{d x^{2}}-m^{2}\left(T_{m}-T_{v}\right)=0,
$$

where, after [53], the following has been considered:

$$
\mathrm{T}_{\mathrm{m}}-\mathrm{T}_{\mathrm{v}}=\left(\mathrm{T}_{\mathrm{m}}-\mathrm{T}_{\mathrm{sat}}\right)-\left(\mathrm{T}_{\mathrm{v}}-\mathrm{T}_{\mathrm{sat}}\right)=\Delta \mathrm{T}_{\mathrm{m}, \mathrm{sat}}-\Delta \mathrm{T}^{*},
$$

where $T_{v}$ is the temperature in the vertical channel of the groove. It has been assumed as equal to the temperature inside a vapor bubble created there. $\mathrm{T}_{\mathrm{m}}$ is the temperature that changes along the height of the fin. $\Delta T^{*}$ is a surplus of vapor temperature inside the bubble over the saturation temperature at given pressure, which is necessary for growth of a bubble of diameter $\mathrm{R}$. This value results from the difference between vapor pressure over liquid pressure that is balanced by the surface tension. Thus, in [53] $\Delta \mathrm{T}^{*}$ has been calculated according to the dependency:

$$
\Delta \mathrm{T}^{*}=\frac{2 \mathrm{~T}_{\mathrm{sat}} \sigma}{\mathrm{R} \rho_{\mathrm{v}} \mathrm{r}}
$$

where $r$ is the heat of vaporization, $\sigma$ is the surface tension and $\rho_{\mathrm{v}}$ is the vapor density. The value of $R$ in the case of the current laser treated samples is considered as half the groove width. The value of $m$ in (5) is a function of the heat transfer coefficient, the fin's thermal conductivity $\left(\lambda_{\mathrm{m}}\right)$, its wetted circumference and surface area. For long micro-fins (as in the case of laser textured grooves), covered with a liquid film of thermal conductivity $\left(\lambda_{1}\right)$ of the thickness $\delta_{1}$ (though which heat is assumed to be transferred to the bubbles), $\mathrm{m}$ can be calculated as:

$$
\mathrm{m}^{2}=\frac{2 \lambda_{1}}{\delta_{1} \lambda_{\mathrm{m}} \mathrm{a}},
$$

where a is the fin's width as in Figure 1. The general solution of (5) will take the form of:

$$
\mathrm{T}_{\mathrm{m}}-\mathrm{T}_{\mathrm{v}}=\mathrm{C}_{1} \mathrm{e}^{\mathrm{mx}}+\mathrm{C}_{2} \mathrm{e}^{-\mathrm{mx}},
$$




$$
\frac{\mathrm{d}\left(\mathrm{T}_{\mathrm{m}}-\mathrm{T}_{\mathrm{v}}\right)}{\mathrm{dx}}=\mathrm{m} \mathrm{C}_{1} \mathrm{e}^{\mathrm{mx}}-\mathrm{m} \mathrm{C}_{2} \mathrm{e}^{-\mathrm{mx}}
$$

The constants can be determined from the following boundary conditions:

$$
\begin{aligned}
& \text { 1. } x=0, T_{m}-T_{v}=\theta-\Delta T^{*}, \\
& \text { 2. } x=h+\frac{a}{2}, \frac{d\left(T_{m}-T_{v}\right)}{d x}=0
\end{aligned}
$$

Thus, $\mathrm{C}_{1}$ and $\mathrm{C}_{2}$ have been determined and, having considered the equation for heat flux of a micro-fin according to Fourier's law:

$$
q=-\left.\lambda_{m} \frac{d\left(T_{m}-T_{v}\right)}{d x}\right|_{x=0}
$$

Thus, the following formula is generated:

$$
\mathrm{q}=\lambda_{\mathrm{m}} \mathrm{m}\left(\theta-\Delta \mathrm{T}^{*}\right) \operatorname{tgh}\left[\mathrm{m}\left(\mathrm{h}+\frac{\mathrm{a}}{2}\right)\right]
$$

In [53] tanh was considered to equal 1 (due to the fact that no impact of the height of the microstructure was observed]. However, the present research results of laser processed specimens do not support this assumption. Thus, the hyperbolic tangent was extended into series for the argument value up to $\pi / 2$ and limited to the first element. Having introduced $m$ into the equation, heat flux of the micro-fin can be calculated as:

$$
\mathrm{q}=\frac{2 \lambda_{1}}{\delta_{1} \mathrm{a}}\left(\mathrm{h}+\frac{\mathrm{a}}{2}\right)\left(\theta-\Delta \mathrm{T}^{*}\right)
$$

It needs to be noted that heat transfer occurs on the whole surface. The area covered by micro-fins is a fraction $1-\varepsilon$ of the total area (where $\varepsilon$ can be regarded as surface porosity). The rest $(\varepsilon)$ is laser textured. It is assumed that it is also covered with liquid film of the thickness $\delta_{1}$. Having considered the above, the total heat flux value dissipated from the area filled with micro-fins can be determined from the following formula:

$$
\mathrm{q}=\frac{2 \lambda_{1}}{\delta_{1} \mathrm{a}}\left(\mathrm{h}+\frac{\mathrm{a}}{2}\right)(1-\varepsilon)\left(\theta-\Delta \mathrm{T}^{*}\right)+\frac{\lambda_{1} \varepsilon}{\delta_{1}}\left(\theta-\Delta \mathrm{T}^{*}\right),
$$

Smirnov [53] assumed that the liquid film thickness $\delta_{1}$ is constant. However, this statement might not be very accurate. The value of the film thickness, according to Xin and Chao's model [36], is dependent on wall superheat, liquid thermal conductivity and viscosity. Thus, the following dependency has been assumed in the current correlation:

$$
\delta_{1} \sim C \operatorname{Pr}^{\mathrm{t}}\left(\theta-\Delta \mathrm{T}^{*}\right)^{\mathrm{n}}
$$

Having considered the above formula, the heat flux dissipated from the laser treated surfaces can be determined from the following equation:

$$
\mathrm{q}=\operatorname{CPr}^{\mathrm{t}}\left[\frac{2 \lambda_{\mathrm{l}}}{\mathrm{a}}\left(\mathrm{h}+\frac{\mathrm{a}}{2}\right)(1-\varepsilon)+\lambda_{\mathrm{l}} \varepsilon\right]\left(\theta-\Delta \mathrm{T}^{*}\right)^{\mathrm{n}},
$$

where $\mathrm{C}, \mathrm{n}$ and $\mathrm{m}$ are experimental constants. Their values have been obtained through fitting of the experimental data provided in Section 3.1. and yield: $C=1902, t=1.44$ and $n=1.76$. Figure 12 presents the comparison of the calculated and experimental test results for the samples considered in the study. 


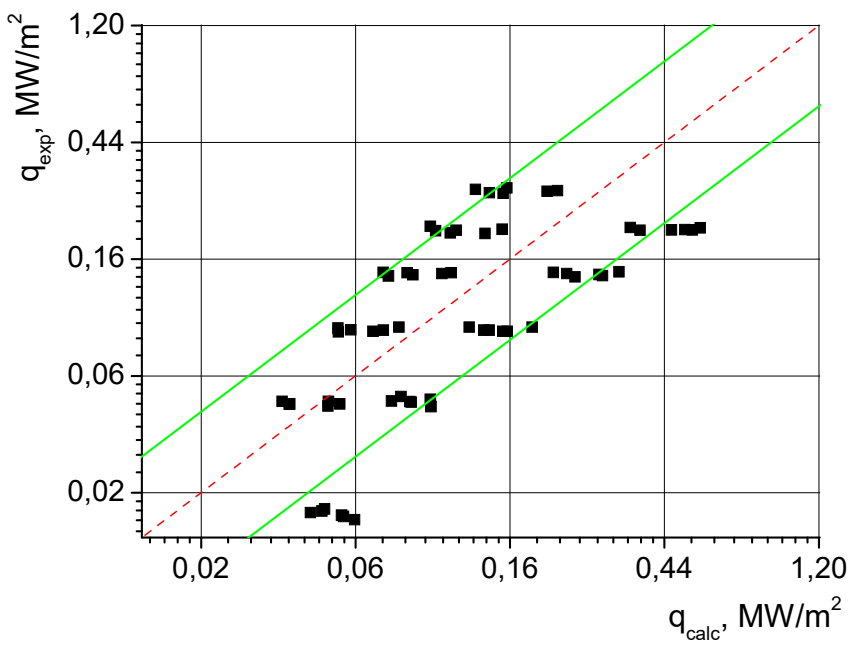

Figure 12. Comparison of the calculated and experimental test results for the laser textured surfaces and both boiling agents.

The comparison of the heat flux experimental data and calculation results according to the modified correlation fall largely within the $\pm 100 \%$ error band. The performance of the laser textured surfaces was significantly affected by the presence of rough and cavity rich areas developed with the laser beam. This phenomenon might be responsible for the spread of experimental data and calculation results as evidenced in the above figure.

\section{Conclusions}

Laser texturing provided considerable enhancement of pool boiling heat transfer, which was evidenced by a shift of the boiling curves for the laser processed samples to the region of low superheats. The surface geometry and microgeometry of the specimens proved to have a significant impact on the heat flux. For both boiling agents the groove depth largely affected the heat flux values with deeply grooved samples performing better. Moreover, the textured surface ratio proved to have a noticeable impact on the boiling process-most probably due to significant roughness generated by the laser treatment and the presence of cavities on the surface. It resulted in increased active nucleation site density, which can considerably affect the performance of such heaters.

In the correlation of the experimental data, modifications to the original model have been introduced and consist mainly of the recognition of the impact of the micro-fins' height, assumption of variable liquid film thickness as well as consideration of heat transfer on the tips. The spread of experimental data and calculation results is undoubtedly related to the surface morphology change in the area modified by the laser treatment due to the development of considerably increased roughness and the presence of cavities.

Laser treatment enables the production of highly efficient phase-change heat exchangers. The possibility of a significant heat transfer enhancement and the relative ease at which surfaces can be modified and shaped into different forms and dimensions can be considered the greatest advantages of laser texturing. Additionally, this treatment method might produce more durable surfaces than in the case of other passive techniques (e.g., sintered powders, meshes). Consequently, it can be better suited to applications, where heat exchangers operate in vibration environments. Thus, the research work in this area offers practical and engineering value as well.

Author Contributions: Conceptualization, Ł.J.O.; methodology, Ł.J.O.; software, Ł.J.O., N.R., J.P. and M.S.; literature review, Ł.J.O.; investigation, Ł.J.O.; resources, Ł.J.O., N.R., J.P. and M.S.; writing-original draft preparation, Ł.J.O.; writing-review and editing, Ł.J.O. and N.R., funding acquisition, Ł.J.O., N.R., J.P. and M.S. All authors have read and agreed to the published version of the manuscript.

Funding: This research was financed with funding from the Polish Ministry of Science and Higher Education. 
Conflicts of Interest: The authors declare no conflict of interest.

\section{Nomenclature}

List and explanation of the nomenclature and symbols.

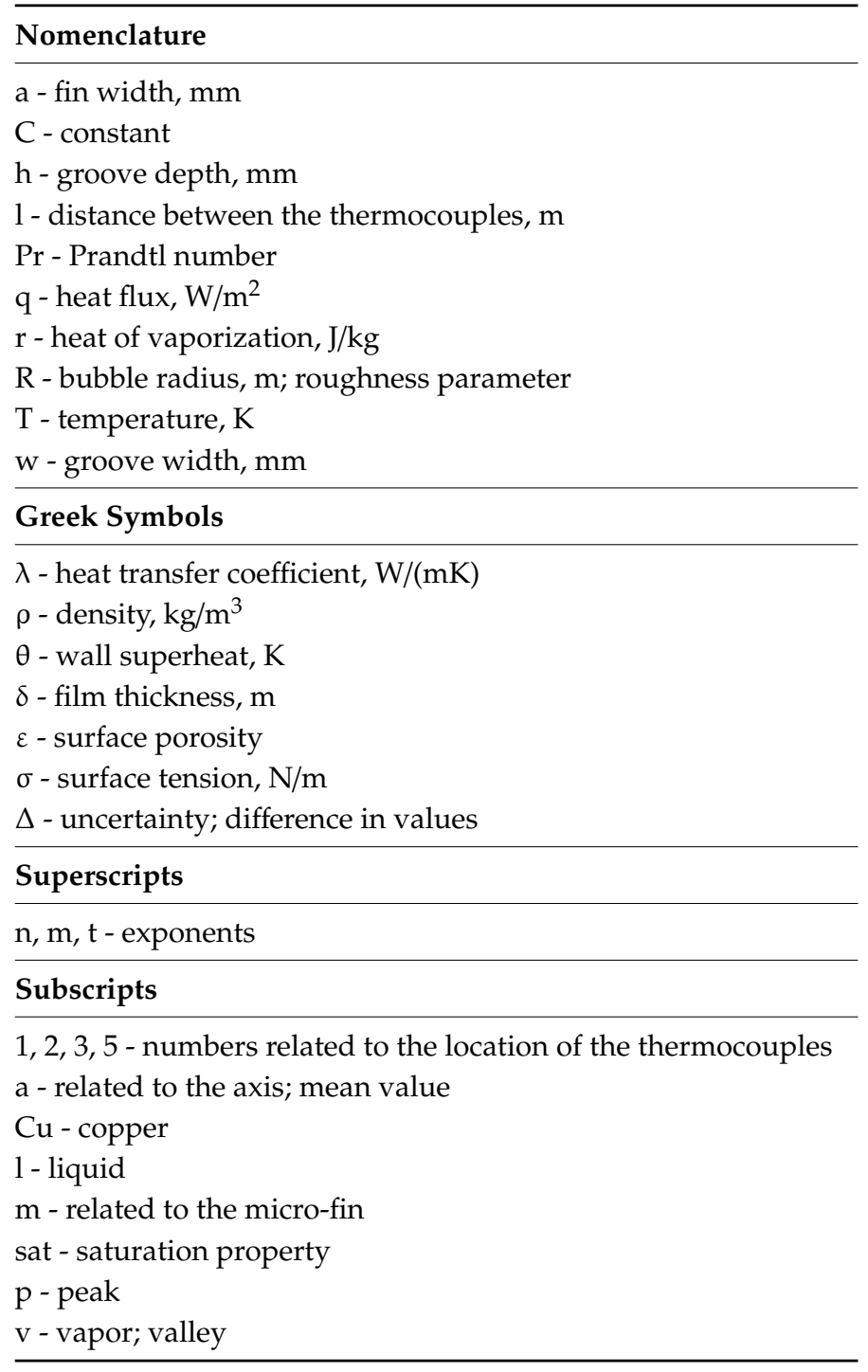

\section{References}

1. Bergles, A.E. Enhancement of pool boiling. Int. J. Refrig. 1997, 20, 545-551. [CrossRef]

2. Bergles, A.E. Techniques to enhance heat transfer. In Handbook of Heat Transfer; Rohsenow, W.M., Hartnett, J.P., Cho, Y.I., Eds.; McGraw-Hill: New York, NY, USA, 1998; pp. 1-76.

3. Khan, S.A.; Atieh, M.A.; Muammer Koç, M. Micro-nano scale surface coating for nucleate boiling heat transfer: A critical review. Energies 2018, 11, 3189. [CrossRef]

4. Dedov, A.V. A review of modern methods for enhancing nucleate boiling heat transfer. Therm. Eng. 2019, 66, 881-915. [CrossRef]

5. Mehralizadeh, A.; Reza Shabanian, A.; Bakeri, G. Effect of modified surfaces on bubble dynamics and pool boiling heat transfer enhancement: A review. Therm. Sci. Eng. Prog. 2020, 15, 100451. [CrossRef]

6. Kruse, C.M.; Anderson, T.; Wilson, C.; Zuhlke, C.; Alexander, D.; Gogos, G.; Ndao, S. Enhanced pool-boiling heat transfer and critical heat flux on femtosecond laser processed stainless steel surfaces. Int. J. Heat Mass Transf. 2015, 82, 109-116. [CrossRef] [PubMed] 
7. Ho, J.Y.; Wong, K.K.; Leong, K.C.; Yang, C. Nucleate pool boiling from selective laser melted microgrooves/microcavities surfaces with HFE-7000. In Proceedings of the First Thermal and Fluids Engineering Summer Conference, New York, NY, USA, 9-12 August 2015.

8. Ho, J.Y.; Wong, K.K.; Leong, K.C. Saturated pool boiling of FC-72 from enhanced surfaces produced by Selective Laser Melting. Int. J. Heat Mass Transf. 2016, 99, 107-121. [CrossRef]

9. Liu, B.; Zhang, Y.; Wei, J.; Wang, W. Experimental and theoretical study of pool boiling heat transfer and its CHF mechanism on femtosecond laser processed surfaces. Int. J. Heat Mass Transf. 2019, 132, 259-270. [CrossRef]

10. Voglar, J.; Gregorčič, P.; Zupančič, M.; Golobič, I. Boiling performance on surfaces with capillary-length-spaced one- and two-dimensional laser-textured patterns. Int. J. Heat Mass Transf. 2018, 127, 1188-1196. [CrossRef]

11. Zakšek, P.; Zupančič, M.; Gregorčič, P.; Golobič, I. Investigation of nucleate pool boiling of saturated pure liquids and ethanol-water mixtures on smooth and laser-textured surfaces. Nanosc. Microsc. Thermophys. Eng. 2020, 24, 29-42. [CrossRef]

12. Gregorčič, P.; Zupančič, M.; Golobič, I. Scalable surface microstructuring by a fiber laser for controlled nucleate boiling performance of high- and low-surface- tension fluids. Sci. Rep. 2018, 8, 7461. [CrossRef]

13. Zupančič, M.; Može, M.; Gregorčič, P.; Golobič, I. Nanosecond laser texturing of uniformly and non-uniformly wettable micro structured metal surfaces for enhanced boiling heat transfer. Appl. Surf. Sci. 2017, 399, 480-490. [CrossRef]

14. Zupančič, M.; Može, M.; Gregorčič, P.; Sitar, A.; Golobič, I. Evaluation of enhanced nucleate boiling performance through walltemperature distributions on PDMS-silica coated and non-coated laser textured stainless steel surfaces. Int. J. Heat Mass Transfer 2017, 111, 419-428. [CrossRef]

15. Zupančič, M.; Steinbücher, M.; Gregor, P.; Golobič, I. Enhanced pool-boiling heat transfer on laser-made hydrophobic/superhydrophilic polydimethylsiloxane-silica patterned surfaces. Appl. Therm. Eng. 2015, 91, 288-297. [CrossRef]

16. Sitar, A.; Moze, M.; Crivellari, M.; Schille, J.; Golobic, I. Nucleate pool boiling heat transfer on etched and laser structured silicon surfaces. Int. J. Heat Mass Transf. 2020, 147, 118956. [CrossRef]

17. Može, M.; Zupančič, M.; Hočevar, M.; Golobič, I.; Gregorčič, P. Surface chemistry and morphology transition induced by critical heat flux incipience on laser-textured copper surfaces. Appl. Surf. Sci. 2019, 490, 220-230. [CrossRef]

18. Grabas, B. Vibration-assisted laser surface texturing of metals as a passive method for heat transfer enhancement. Exp. Therm. Fluid Sci. 2015, 68, 499-508. [CrossRef]

19. Karthikeyan, A.; Coulombe, S.; Kietzig, A.M. Boiling heat transfer enhancement with stable nanofluids and laser textured copper surfaces. Int. J. Heat Mass Transf. 2018, 126, 287-296. [CrossRef]

20. Dharmendra, M.; Suresh, S.; Hafiz, M.A.; Udaya Kumar, G. Investigation to improve the pool boiling heat transfer characteristics using laser-textured copper-grooved surfaces. Int. J. Photoenergy 2020, 2020, 3846157. [CrossRef]

21. Nirgude, V.V.; Santosh, S.K. Enhancement in nucleate pool boiling heat transfer on nano-second laser processed copper surfaces. Exp. Heat Transf. 2018, 32, 566-583. [CrossRef]

22. Orzechowski, T. Boiling heat transfer on the fin with laser modified surface. In Proceedings of the International Symposium on Convective Heat and Mass Transfer in Sustainable Energy, Yasmine Hammamet, Tunisia, 26 April-1 May 2009; pp. 1-14.

23. Wong, K.K.; Leong, K.C. Saturated pool boiling enhancement using porous lattice structures produced by Selective Laser Melting. Int. J. Heat Mass Transf. 2018, 121, 46-63. [CrossRef]

24. Zhang, C.; Zhang, L.; Xu, H.; Li, P.; Qian, B. Performance of pool boiling with 3D grid structure manufactured by selective laser melting technique. Int. J. Heat Mass Transf. 2019, 128, 570-580. [CrossRef]

25. Piasecka, M.; Strakk, K.; Grabas, B. Vibration-assisted laser surface texturing and electromachining for the intensification of boiling heat transfer in a minichannel. Arch. Metall. Mater. 2017, 62, 1983-1990. [CrossRef]

26. Ventola, L.; Fasano, M.; Cappabianca, R.; Bergamasco, L.; Clerici, F.; Luciano Scaltrito, L.; Chiavazzo, E.; Asinaro, P. Convective heat transfer enhancement through laser-etched heat sinks: Elliptic scale-roughened and cones patterns. Energies 2020, 13, 1360. [CrossRef]

27. Ventola, L.; Scaltrito, L.; Ferrero, S.; Maccioni, G.; Chiavazzo, E.; Asinari, P. Micro-structured rough surfaces by laser etching for heat transfer enhancement on flush mounted heat sinks. J. Phys. Conf. Ser. 2014, 525, 012017. [CrossRef] 
28. Pastuszko, R.; Kaniowski, R.; Wójcik, T.M. Comparison of pool boiling performance for plain micro-fins and micro-fins with a porous layer. Appl. Therm. Eng. 2020, 166, 114658. [CrossRef]

29. Pastuszko, R. Pool boiling on micro-fin array with mesh structures. Int. J. Therm. Sci. 2010, 49, $2289-2298$. [CrossRef]

30. Kline, S.J.; McClintock, F.A. Describing uncertainties in single sample experiments. Mech. Eng. Am. Soc. Mech. Eng. 1953, 75, 3-8.

31. Rohsenow, W.M. A method of correlating heat transfer data for surface boiling of liquids. Trans. ASME 1952, 74, 969-975.

32. Pioro, I.L. Experimental evaluation of constants for the Rohsenow pool boiling correlation. Int. J. Heat Mass Transf. 1999, 42, 2003-2013. [CrossRef]

33. Stephan, K.; Abdelsalam, M. Heat transfer correlations for natural convection boiling. Int. J. Heat Mass Transf. 1980, 23, 73-87. [CrossRef]

34. Zhao, X.; Zhang, H. Experimental study of pool boiling heat transfer from powder porous surface at higher heat fluxes. In Advances in Phase Change Heat Transfer; Xin, M., Ed.; Pergamon Press: Oxford, UK, 1988; pp. 236-241.

35. Li, C.; Peterson, G.P.; Wang, Y. Evaporation/boiling in thin capillary wicks (I)—Wick thickness effects. J. Heat Transf. 2006, 128, 1312-1319. [CrossRef]

36. Xin, M.-D.; Chao, Y.-D. Analysis and experiment of boiling heat transfer on T-shaped finned surfaces. Chem. Eng. Commun. 1987, 50, 185-199. [CrossRef]

37. Liang, G.; Mudawar, I. Review of pool boiling enhancement by surface modification. Int. J. Heat Mass Transf. 2019, 128, 892-933. [CrossRef]

38. Rioux, R.P.; Nolan, E.C.; Li, C.H. A systematic study of pool boiling heat transfer on structured porous surfaces: From nanoscale through microscale to macroscale. AIP Adv. 2014, 4, 117133. [CrossRef]

39. Orman, Ł. Enhanced boiling heat transfer on surfaces covered with microstructural mesh coatings. Jord. J. Mech. Ind. Eng. 2019, 13, 155-160.

40. Beitel, G.R. Boiling Heat-Transfer Processes and Their Application in the Cooling of High Heat Flux Devices; Arnold Engineering Development Center: Arnold, TN, USA, 1993.

41. Kotthoff, S.; Gorenflo, D. Pool boiling heat transfer to hydrocarbons and ammonia: A state-of-the-art review. Int. J. Refrig. 2008, 31, 573-602. [CrossRef]

42. Benjamin, R.J.; Balakrishnan, A.R. Nucleation site density in pool boiling of saturated pure liquids: Effect of surface microroughness and surface and liquid physical properties. Exp. Therm. Fluid Sci. 1997, 15, 32-42. [CrossRef]

43. Kamel, M.S.; Lezsovits, F. Enhancement of pool boiling heat transfer performance using dilute cerium oxide/water nanofluid: An experimental investigation. Int. Commun. Heat Mass Transf. 2020, 114, 104587. [CrossRef]

44. Gorenflo, D.; Chandra, U.; Kotthoff, S.; Luke, A. Influence of thermophysical properties on pool boiling heat transfer of refrigerants. Int. J. Refrig. 2004, 27, 492-502. [CrossRef]

45. Cai, S.Q.; Bhunia, A. Effect of liquid properties on phase-change heat transfer in porous wick structures. J. Heat Transf. 2016, 138, 1-7. [CrossRef]

46. Surtaev, A.S.; Serdyukov, V.S.; Safonov, A.I. Enhancement of boiling heat transfer on hydrophobic fluoropolymer coatings. Interf. Phenom. Heat Transf. 2018, 6, 269-276. [CrossRef]

47. Gao, M.; Kong, P.; Zhang, L.-X. Evaporation dynamics of different sizes sessile droplets on hydrophilic and hydrophobic heating surface under constant wall heat fluxes conditions. Int. Commun. Heat Mass Transf. 2018, 93, 93-99. [CrossRef]

48. Seok, J.H.; An, S.; Goo Park, H.; Kim, M.-W.; Al-Deyab, S.S.; James, S.C.; Choi, J.; Yoon, S.S. Enhancement of critical heat flux and superheat through controlled wettability of cuprous-oxide fractal-like nanotextured surfaces in pool boiling. Int. J. Heat Mass Transf. 2017, 107, 105-111. [CrossRef]

49. Jo, H.; Ahn, H.S.; Kang, S.; Kim, M.H. A study of nucleate boiling heat transfer on hydrophilic, hydrophobic and heterogeneous wetting surfaces. Int. J. Heat Mass Transf. 2011, 54, 5643-5652. [CrossRef]

50. Yim, K.; Lee, J.; Naccarato, B.; Kim, K.J. Surface wettability effect on nucleate pool boiling heat transfer with titanium oxide (TiO2) coated heating surface. Int. J. Heat Mass Transf. 2019, 133, 352-358. [CrossRef]

51. Alic, E.; Das, M.; Kaska, O. Heat flux estimation at pool boiling processes with computational intelligence methods. Processes 2019, 7, 293. [CrossRef] 
52. Li, R.; Huang, Z. A new CHF model for enhanced pool boiling heat transfer on surfaces with micro-scale roughness. Int. J. Heat Mass Transf. 2017, 109, 1084-1093. [CrossRef]

53. Smirnov, G.F. Približennaja teorija teploobmena pri kipenii na poverchnostjach pokrytych kapilljarno-Poristymi strukturami. Teploenergetika 1977, 9, 77-80.

(c) (

(C) 2020 by the authors. Licensee MDPI, Basel, Switzerland. This article is an open access article distributed under the terms and conditions of the Creative Commons Attribution (CC BY) license (http://creativecommons.org/licenses/by/4.0/). 